Natural Hazards and Earth System Sciences, 5, 425-437, 2005

SRef-ID: 1684-9981/nhess/2005-5-425

European Geosciences Union

(C) 2005 Author(s). This work is licensed

under a Creative Commons License.

\title{
Contribution of multi-temporal remote sensing images to characterize landslide slip surface - Application to the La Clapière landslide (France)
}

\author{
B. Casson, C. Delacourt, and P. Allemand \\ Laboratoire Sciences de la Terre - UCB and ENS-LYON 1, France \\ Received: 12 July 2004 - Revised: 13 March 2005 - Accepted: 8 April 2005 - Published: 30 May 2005 \\ Part of Special Issue "Landslides and debris flows: analysis, monitoring, modeling and hazard"
}

\begin{abstract}
Landslide activity is partly controlled by the geometry of the slip surface. This activity is traduced at the surface by displacements and topographic variations. Consequently, multi-temporal remote sensing images can be used in order to characterize the geometry of landslide slip surface and its spatial and temporal evolution. Differential Digital Elevation Models (DEMs) are obtained by subtracting two DEMs of different years. A method of multi-temporal images correlation allows to generate displacement maps that can be interpreted in terms of velocity and direction of movements. These data are then used to characterize qualitatively the geometry of the slip surface of the la Clapière landslide (French Southern Alps). Distribution of displacement vectors and of topographic variations are in accordance with a curved slip surface, characterizing a preferential rotational behaviour of this landslide. On the other hand, a spatial and temporal evolution of the geometry of the slip surface is pointed out. Indeed, a propagation of the slip surface under the Iglière bar, in the $\mathrm{W}$ part of the landslide, is suspected and can be linked to the acceleration of the landslide in 1987. This study shows the high potential of multi-temporal remote sensing images for slip surface characterization. Although this method could not replace in situ investigations, it can really help to well distribute geophysical profiles or boreholes on unstable areas.
\end{abstract}

\section{Introduction}

Landslide activity is controlled by external parameters like precipitations, erosion or run-off and internal parameters, among which the geometry of the slip surface and its spatial and temporal evolution play an important role. Dis-

Correspondence to: B. Casson

(berangere.casson@ cegetel.net) placements and vertical topographic variations traduce this activity at the surface. The depth and the geometry of the slip surface are usually measured directly on boreholes (Scullin, 1994) or indirectly by geophysical investigations (Bogoslovski and Ogilvy, 1977; Mauritsch et al., 2000; Israil and Pachauri, 2003). Nevertheless, these techniques which require field operators are often difficult to apply on unstable area. Moreover, they give results limited to the area and to the period of investigation (Maquaire et al., 2001).

An alternative possibility is to use surface data like displacement fields and vertical variations of topography to characterize the geometry of the slip surface (Hutchinson, 1983; Bishop, 1999). This has been done using balanced cross sections to evaluate the depth of the slip surface (Ehlert, 1986), from surface displacements and depletion volumes. Nevertheless, these works concern only translational cases (Bishop, 1999).

Surface displacements can be directly measured on the field on few points, using tacheometric techniques or GPS methods (Gili et al., 2000; Malet et al., 2002; Rizzo, 2002; Squarzoni et al., 2005). Despite their high accuracy, these measurements have a low spatial resolution and they require the access to the site. Remote sensing is then a powerful tool for improving the spatial resolution of measurements, without in situ investigations. SAR interferometry has pointed out its high potential for detection (Fruneau et al., 1996), kinematic characterization (Berardino et al., 2003; Squarzoni et al., 2003) and modelling (Fruneau et al., 1996) of landslides. However, these supports exist only since 1991 and geometric and environmental constraints limit their use in mountain context (Hanssen, 2001). Aerial photographs can be used to overcome these problems. These images have a temporal and a spatial resolution adapted to landslide studies. Moreover, these kinds of images are acquired for 50 years. They are currently used to generate Digital Elevation 

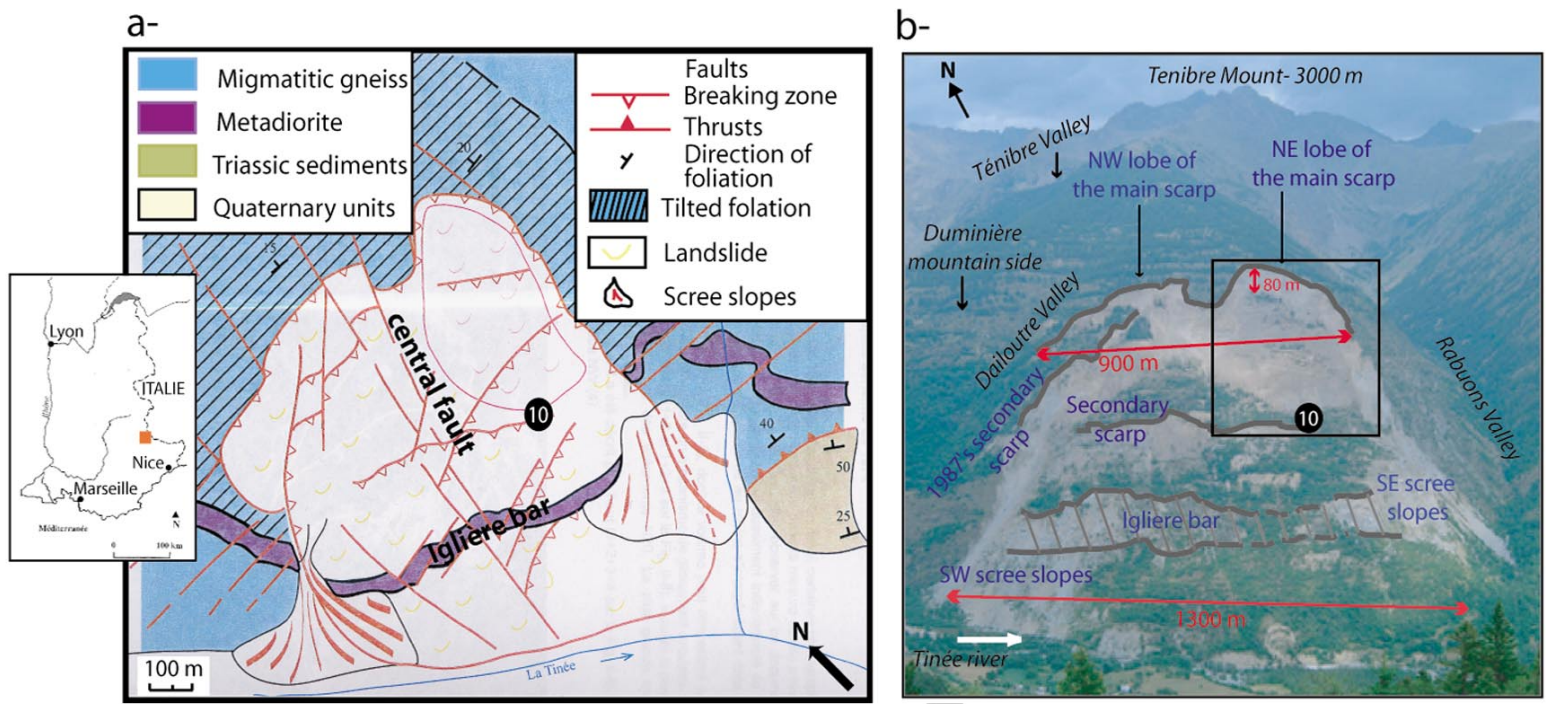

superimposed landslide

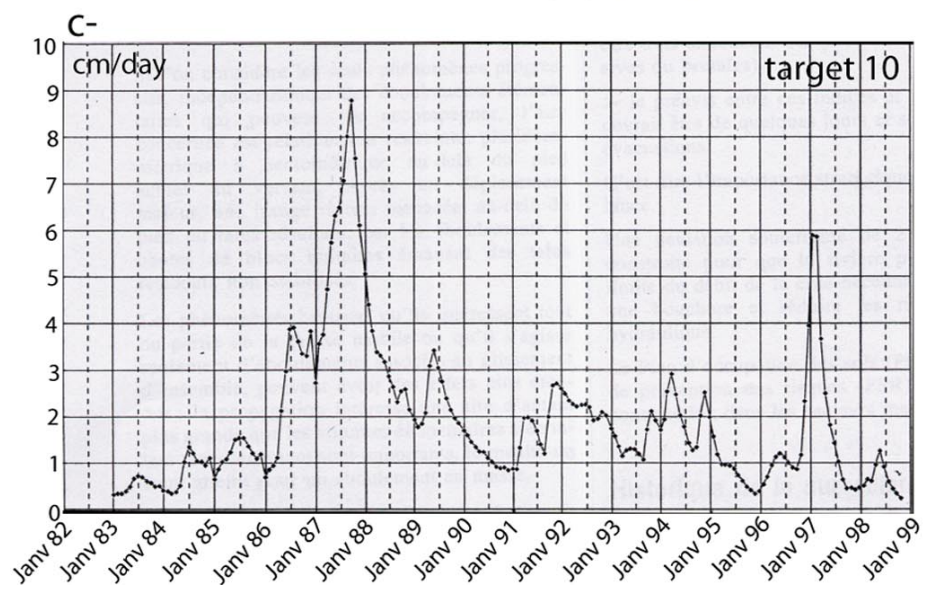

Fig. 1. The la Clapière landslide: (a) lithology and structure of the landslide, (b) morphology of the landslide (from Quenot, 2000), (c) EDM of the target 10 (from Follacci, 1999).

Models (DEMs) and ortho-rectified images, in order to detect and to follow landslide activity (Weber and Herrmann, 2000; Casson et al., 2003; Van Westen and Lulie Getahan, 2003).

This paper presents a methodology of slip surface characterization using surface measurements. The processing of surface data generation is also detailed. Then, a qualitative analysis of these multi-temporal remote sensing data is realised to characterize the slip surface geometry of the La Clapière landslide (French Southern Alps) and its spatial and temporal evolution.

\section{The La Clapière landslide}

The La Clapière landslide is located in the French Southern Alps (Fig. 1), downstream from the village of Saint-Etiennede-Tinée, on the boundary of the Mercantour massif. This landslide affects an area of about 100 ha between 1100 and $1800 \mathrm{~m}$ of elevation (Fig. 1b). La Clapière is affected by average movements of $1 \mathrm{~cm} /$ day since 1982 (Fig. 1c).
The landslide affects the hercynian basement rocks (Fig. 1a) composed mainly by migmatitic gneiss (Follacci et al., 1988b). A subhorizontal level of metadiorite, called "barre d'Iglière", crosses the landslide at an average elevation of $1350 \mathrm{~m}$ (Figs. 1a and 1b). All geological units present a hercynian foliation with a near subhorizontal strike at the surroundings of the landslide and a $10-30^{\circ} \mathrm{NE}$ strike within the landslide (Follacci et al., 1988a; Gunzburger and Laumonier, 2002). The landslide area is very fractured with three major directions of faults (Guglielmi et al., 2000), which are $\mathrm{N} 10-30^{\circ} \mathrm{E}, \mathrm{N} 90^{\circ} \mathrm{E}$ and $\mathrm{N} 110-140^{\circ} \mathrm{E}$ (Fig. 1a). A fault with a N20 direction divides the landslide in two parts by the middle (Fig. 1a).

The landslide is bounded at the top by a $80 \mathrm{~m}$ high main scarp divided in two parts, called "lobes" (Follacci, 1987). Two secondary scarps have been developed within the landslide. One, with a N120 direction, is located at an average elevation of $1500 \mathrm{~m}$ and another one is developed along a N90 fault since 1987, just under the top NW lobe (Fig. 1b). A hectometric landslide superimposed on the major one affects 

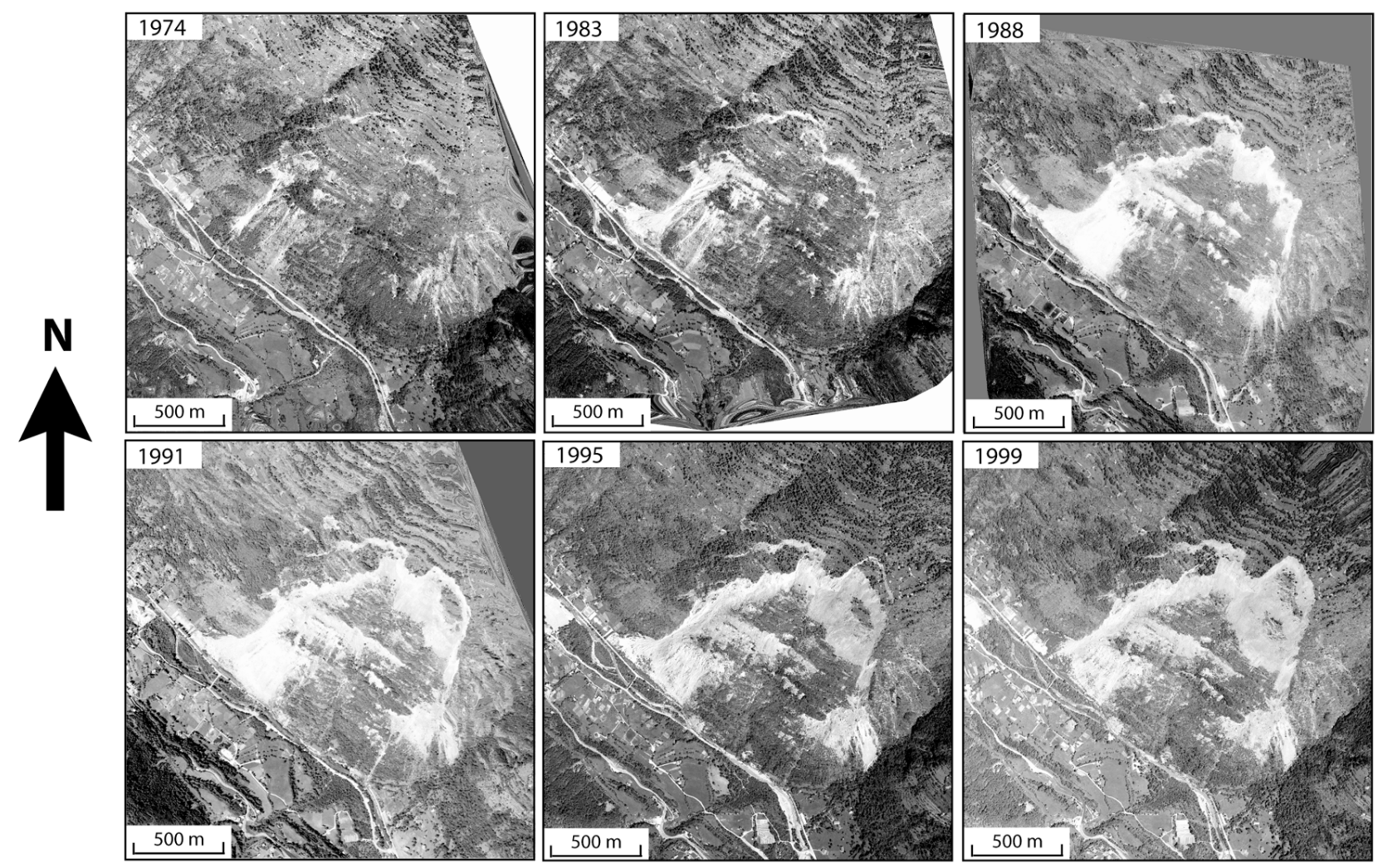

Fig. 2. Six ortho-rectified images of the la Clapière landslide for the time interval 1974-1999.

the upper NE lobe (Fig. 1b). The upper part of the landslide between the headscarp and the "barre d'Iglière" has a characteristic morphology in decametric steps (Follacci, 1987; Gunzburger, 2001). These structures have a geological origin (Gunzburger, 2001). Morphologic characteristics of the la Clapière landslide are in favour of a rotational movement of this unstable area (Varnes, 1978; Follacci, 1987).

This landslide is probably active for one century. Recent datings even propose an age of about 10000 years (BigotCormier et al., 2003). First studies of the La Clapière landslide have been realized in 1977. Electronic Distance Measurements (EDM) are regularly acquired since 1982 . These data point out velocities of about $1 \mathrm{~cm} /$ day. Two accelerations have been registered: one during autumn of 1987 with velocities greater than $10 \mathrm{~cm} /$ day and one at the beginning of 1997 with velocities greater than $5 \mathrm{~cm} /$ day (Follacci, 1999) (Fig. 1c). Moreover, EDM point out a seasonal response of the landslide characterized by an acceleration of movements correlated to snow melting (Follacci, 1987; Follacci et al., 1988b) (Fig. 1c). For a few years, EDM are combined with different other investigations: hydro-geological studies (Compagnon et al., 1997; Guglielmi et al. 2000), remote sensing (Fruneau et al., 1996; Serratrice, 2001; Casson et al., 2003; Squarzoni, 2003) and subsurface geophysical investigations (Lebourg et al., 2003). Different types of geometrical, mechanical or hydro-mechanical models have been derived from this data set (Fruneau et al., 1996; Soukatchoff and Guglielmi, 2001; Cappa et al., 2004), but actually none follows the evolution of the slip surface geometry.

EDM have been used by Follacci in 1987 in order to realize a conceptual model of landslide activity. In his opinion, the La Clapière landslide progressively evolves from (1) an unorganized stage with a discontinue slip surface to (2) a rotational landslide. Furthermore, Follacci (1987) observes different parts within the landslide which belongs to different stages of evolution. These parts are limited by structural or lithologic boundaries, like the N20 central fault or the "barre d'Iglière" (Fig. 1a). He points out two areas: the E part of the N20 central fault is characterized by ancient and fast movements whereas the $\mathrm{W}$ part is affected by more recent and slower displacements. Using these observations and geological considerations, he suggests that the E part belongs to the rotational stage of the landslide with a continue slip surface from top to bottom of the landslide. On the other hand, the $\mathrm{W}$ part of the N20 central fault is associated to the first stage characterized by a discontinue slip surface, which only extends from the top of the landslide to the "barre d'Iglière". The area of the central fault accommodates differential displacements.

EDM show that displacement vectors are all parallel and that accelerations are synchronous within the landslide. This suggests a deep movement (Follacci, 1987) of this landslide, evaluated to more than $50 \mathrm{~m}$ depth, using the surface of the landslide of 100 ha and its estimated volume about $50.10^{6} \mathrm{~m}^{3}$ (Follacci, 1999). 
Table 1. Characteristics of raw images, DEMs generated from these images and final reoriented supports.

\begin{tabular}{|c|c|c|c|c|c|c|}
\hline & 1974 & 1983 & 1988 & 1991 & 1995 & 1999 \\
\hline Initial resolution of raw images (m) & 0.69 & 0.74 & 1.21 & 1.01 & 0.96 & 0.94 \\
\hline Scale of raw images & $1: 17000$ & $1: 17000$ & $1: 30000$ & $1: 30000$ & $1: 20000$ & $1: 25000$ \\
\hline \multicolumn{7}{|l|}{ Relative precision (m) } \\
\hline $\mathrm{X}$ & 0.3 & 0.2 & 1.1 & 0.6 & 0.3 & 0.4 \\
\hline $\mathrm{Y}$ & 0.4 & 0.2 & 0.6 & 0.5 & 0.3 & 0.6 \\
\hline $\mathrm{Z}$ & 1.2 & 1.0 & 2.2 & 1.7 & 1.0 & 1.3 \\
\hline mean & 0.6 & 0.5 & 1.3 & 0.9 & 0.5 & 0.7 \\
\hline \multicolumn{7}{|l|}{ Absolute accuracy (m) } \\
\hline$X$ & 4.3 & 6.8 & 9.8 & 7.9 & 4.9 & 6.4 \\
\hline$Y$ & 5.5 & 3.6 & 4.8 & 5.8 & 5.1 & 3.4 \\
\hline$Z$ & 6.9 & 2.7 & 12.3 & 6.2 & 5.6 & 3.6 \\
\hline mean & 5.6 & 4.4 & 8.9 & 6.6 & 5.2 & 4.5 \\
\hline \multicolumn{7}{|l|}{$\begin{array}{l}\text { Precision of orthoimages and DEMs } \\
\text { after the reorientation relative to the } \\
1999 \text { image }(\mathrm{m})\end{array}$} \\
\hline$X$ & 0.7 & 1.2 & 1.7 & 1.3 & 0.9 & - \\
\hline $\mathrm{Y}$ & 0.9 & 1.4 & 1.1 & 1.3 & 1.3 & - \\
\hline $\mathrm{Z}$ & 1.7 & 2.1 & 1.7 & 1.4 & 2.1 & - \\
\hline mean & 1.1 & 1.6 & 1.5 & 1.3 & 1.4 & - \\
\hline
\end{tabular}

\section{Methodology}

Previous studies used displacement maps and differential DEMs derived from optical remote sensing data to monitor landslide activity (Powers et al., 1996; Kääb, 2002; Mora et al., 2003; Van Westen and Lulie Getahun, 2003; Delacourt et al., 2004). Nevertheless, these data can also be used to characterise qualitatively the geometry of landslide slip surface (Hutchinson, 1983; Bishop, 1999). Indeed, distribution of displacement vectors and of vertical topographic variations is function of the slip surface geometry. The study is realised in 2D, along longitudinal cross sections of the landslide, which extend from top to bottom. It is supposed that the landslide behaves as a rigid bloc along each profile. This implies that internal deformation is negligible and that displacement velocities are constant from slip surface to topographic surface. These strong hypotheses, which are not always true, will be discussed later. The slip surface characterisation only takes into account surface data which represent deep processes. Consequently, displacements and topographic variations, registered on scree slopes, and which are related to superficial processes, are not used. First, surface data processing is explained. Then, conceptual models, which relate distribution of displacements and of topographic variations to slip surface geometry, are described.

\subsection{Data set processing}

Six stereoscopic pairs of aerial photographs, acquired above the La Clapière landslide, have been selected from the Institut Géographique National (IGN) data base for the years 1974, 1983, 1988, 1991, 1995 and 1999 (Fig. 2). These im- ages cover a period of 25 years with a temporal resolution ranging from 3 to 9 years. The analogical images are scanned in order to obtain a spatial resolution of about $1 \mathrm{~m}$ (Table 1). For each year, a DEM and an ortho-rectified image are generated. Then differential DEMs and displacement maps are processed between different years.

\subsubsection{DEMs and ortho-rectified images generation}

A three step methodology of DEMs generation from stereoscopic pairs of aerial photographs has been developed (Casson et al., 2003; Casson, 2004). First, position and orientation of acquisition cameras are optimized using a least mean square inversion (Kraus and Waldhaüsl, 1994). Secondly, stereoscopic images are correlated using the MEDICIS correlator, developed by the Centre National des Etudes Spatiales (CNES). This step consists in finding for each point of the first image, the point representing the same object on the second one. Each pair of correlated points is called a pair of homologous points. Finally, DEMs are calculated from camera parameters and homologous point positions. A least mean square inversion is used to improve the intersection of lines of sight of the two cameras (Baratoux et al., 2001; Casson et al., 2003). After this step, the distance between the lines of sight of the two cameras has to be null on each DEM point. Consequently, for each DEM point, the residual shift between the lines of sight, along each component $X, Y$ and $Z$, is used to calculate precision maps (Casson et al., 2003). This relative precision is a standard deviation, which is only function of calculation parameters. It shows the capacity of the methodology to reconstruct topography, in function of entered data (Mikhail et al., 2001). This relative precision 
Table 2. Characteristics and precisions of differential DEMs (with $\mu$ the average and $\sigma$ the standard deviation of data).

\begin{tabular}{llllll}
\hline & $74-83$ & $83-88$ & $88-91$ & $91-95$ & $95-99$ \\
\hline \% of eliminated points by statistic law $(\mu \pm 2 \sigma)$ & 0.368 & 0.390 & 1.113 & 1.133 & 0.046 \\
VA value for differential DEMs $(m)$ & 2.39 & 2.74 & 3.96 & 3.21 & 2.19
\end{tabular}

is opposed to the absolute accuracy which depends on external data. The absolute accuracy corresponds to the shift between the position of one point in the space, given by the DEM, and its real position (Mikhail et al., 2001). The six pairs of aerial photographs are used to generate six DEMs on the la Clapière landslide. In agreement with the resolution of scanned images, these DEMs are interpolated with a metric resolution (Table 1). The relative precision of the DEMs is less than $1.1 \mathrm{~m}$ in planimetry and less than $2.2 \mathrm{~m}$ in altimetry. Their mean absolute accuracy is between 4.4 and $8.9 \mathrm{~m}$ (Table 1).

An ortho-rectified image is a projection of a raw image in an absolute coordinate system, taking topography into account. In our case, each image point can be associated to an absolute position given by the DEM, in a conic conform projection. The raw image is then resampled in the coordinate system of the DEM. The absolute accuracy of ortho-images is equal to the absolute accuracy of DEMs (Table 1).

Nevertheless, measurements of surface displacements and topographic variations above the la Clapière landslide require more precise data. Thus, each orthoimage has been reoriented in the frame of the more recent one. The 1999 image has been chosen as the reference because of its best absolute accuracy (Table 1). The re-orientation uses control points located on stable areas and uniformly distributed around the landslide (Casson et al., 2003; Casson, 2004). These points are used to calculate the distortion between the reference image and the other ones. The components of this geometric transformation are calculated using a least mean square inversion. This transformation is then applied to each DEM point and each ortho-image point. After this reorientation, all DEMs and orthoimages are projected in the same ground coordinate system (Fig. 2). The precision of this re-orientation relative to the 1999 image ranges between 0.7 to $2.1 \mathrm{~m}$ (Table 1).

\subsubsection{Differential DEMs generation}

A differential DEM shows vertical topographic variations on one geographic point, during a defined time interval. For example on Fig. 3, the differential $\Delta z P_{2}$ on the position $H_{2}$ is equal to the difference between the elevation of point $P_{2}$ at time $t_{2}$ and the elevation of the point located on position $\mathrm{H}_{2}$ at time $t_{1}$.

After the reorientation step, DEMs are subtracted two by two. A positive value corresponds to an accumulation of materials, a negative one, to depletion and a null one to transfer or to stability. The differences are close to 0 on stable ar-

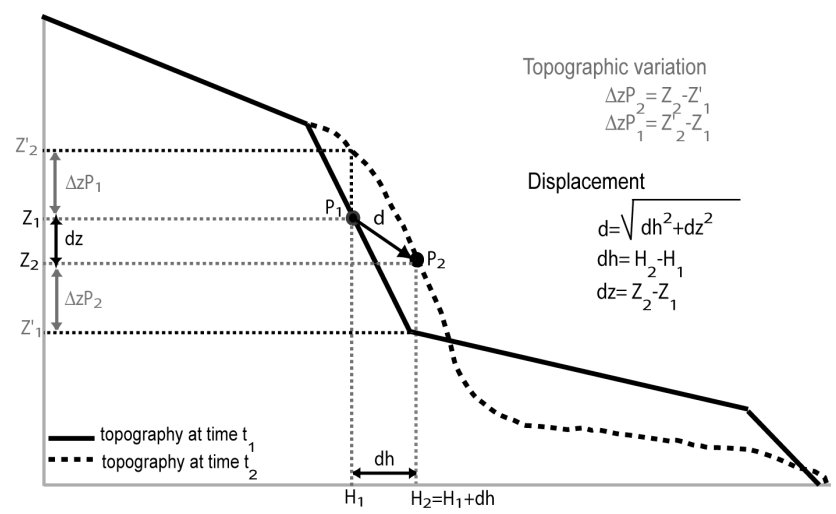

Fig. 3. Definition of displacement and of topographic variation, with $P_{1}$ the point at time $t_{1}, P_{2}$ the same point at time $t_{2}, H_{1}$ the horizontal position of point $P_{1}$ at time $t_{1}, H_{2}$ the horizontal position of point $P_{2}$ at time $t_{2}, Z_{1}$ the elevation of point $P_{1}$ at time $t_{1}, Z_{2}$ the elevation of point $P_{2}$ at time $t_{2}, Z_{1}^{\prime}$ the elevation of point located on $H_{2}$ at time $t_{1}$ and $Z_{2}^{\prime}$ the elevation of point located on $H_{1}$ at time $t_{2}$.

eas, outside the landslide. Differential DEMs have been statistically processed in order to eliminate topographic data of very high amplitude. Extreme values, outside of $\mu \pm 2 \sigma$ (with $\mu$ the average and $\sigma$ the standard deviation of data), are removed. More than $99 \%$ of points for each differential DEM are retained (Table 2).

Differential DEMs can be represented by maps of 3 colours showing ablation, accumulation and transfer/stable areas (Fig. 4a). In order to generate these maps, the vertical precision VA of each point of differential DEMs is defined. It corresponds to the sum of vertical precision of this point on each DEM. These values are extracted from Z-relative precision maps, associated to each DEM. For a given point, if the absolute value of the differential DEM is larger than VA, the topographic variation is significant. It is plotted in blue if it is positive and in red if it is negative (Fig. 4a). On the opposite, if the absolute value of the differential DEM is lower than VA, it is undetermined and plotted in yellow. In this case, the interpretation depends on the velocity of displacements. Indeed, if no displacement is recorded on undetermined areas, the zones are certainly stable. On the opposite if significant movements are recorded, materials are transferred on this zone, without significant changes in topography. For the la Clapière landslide, during the 25 years of the study, VA values are between $2.19 \mathrm{~m}$ and $3.95 \mathrm{~m}$ (Table 2). 


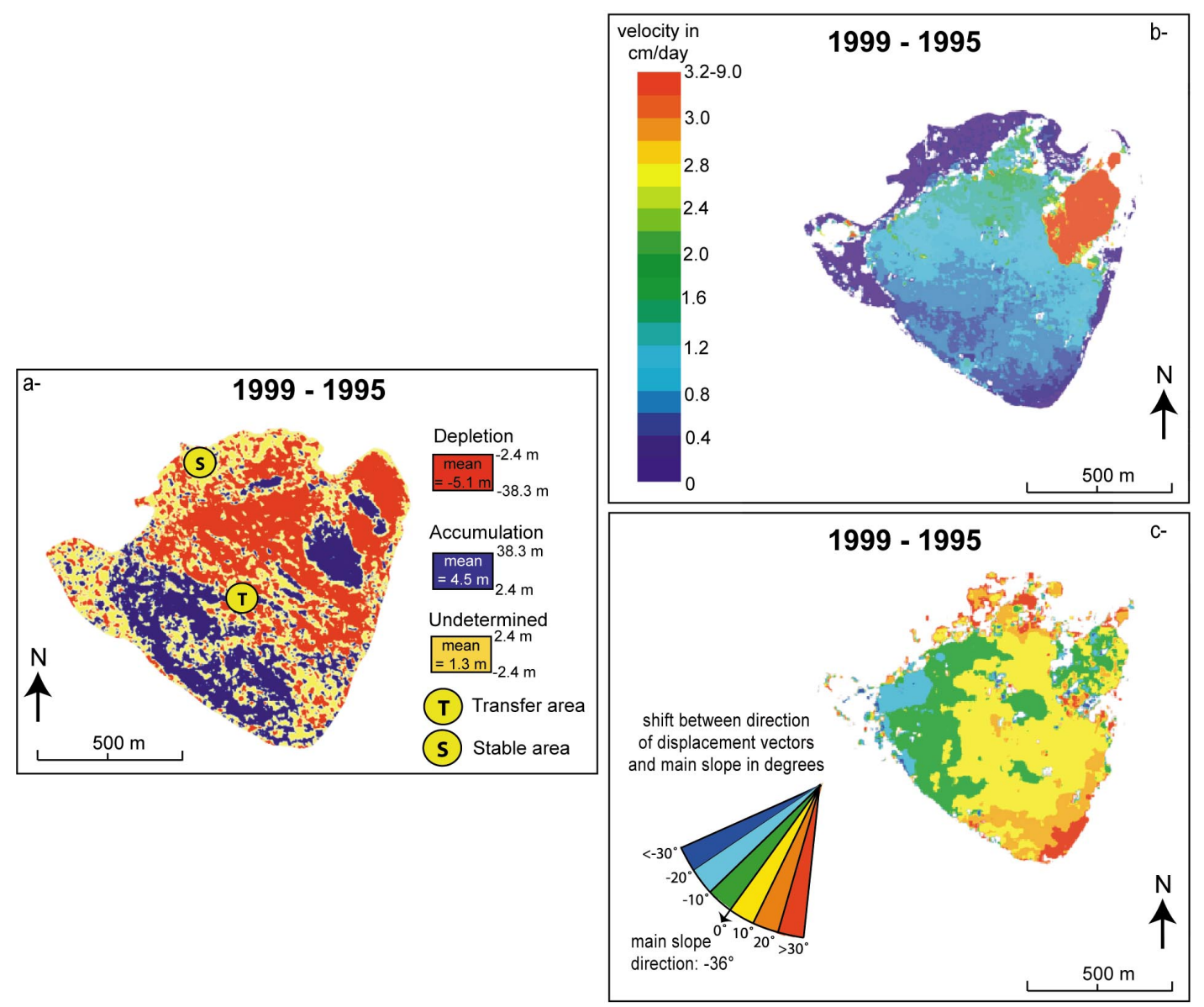

Fig. 4. Surface data extracted from DEMs and orthoimages of the la Clapière landslide: (a) differential DEM represented by a three colors map for the time interval 1995-1999, (b) map of displacement velocities for the time interval 1995-1999, (c) map of displacement directions for the time interval 1995-1999.

\subsubsection{Displacement maps generation}

Orthoimages and associated DEMs are used to calculate the 3D displacement of each point. The displacement $d$ (Fig. 3) is decomposed in a horizontal displacement $d h$ and a vertical one $d z$. The horizontal displacement $d h$ is decomposed in two components $d x$ and $d y$.

The MEDICIS correlator locates two homologous points on two images taken on the same area. Consequently, if two ortho-rectified images of two different dates are correlated, the shift between the position of one point on the reference image and the position of the point representing the same object on the second image is obtained (Vadon and Massonnet, 2002). These shifts multiplied by the resolution of images, which is of $1 \mathrm{~m}$, give the horizontal displacement of each image point during the studied time interval. These kinds of studies have been already realized and validated on glaciers and landslides (Kääb, 2002; Delacourt et al., 2004). Nevertheless, this technique is efficient only if the surface aspect remains stable between the two successive images.

After the correlation phase, the points located outside the landslide have to present a null shift because they are located on stable areas. On the opposite, points located within the landslide can present a shift different from 0 (Fig. 4b). One DEM is available for each ortho-image of each year. So, the $Z$ position of each point before and after the displacement, during a defined time interval, is known. Consequently, as horizontal and vertical components of movement are measured, the 3D displacement of each image point is calculated.

Displacements can be interpreted in terms of velocity and direction. Velocities are obtained by dividing the norm of 3D displacement vectors by time (Fig. 4b). The direction of movement is calculated from the components of horizontal displacement relative to the North direction. Then, these directions are subtracted to the average direction of the main slope of the landslide. Finally, the shift between the direction of displacement vectors and the direction of the main slope of the landslide is available for each image point (Fig. 4c).

The precision of displacement depends on the relative precision of each DEM, their absolute accuracy, the precision obtained after the re-orientation step and the precision of the correlation phase. A mathematic formulation of this total precision appears complex. So it was decided to realize a practical evaluation of the final precision of velocity maps. Indeed, stable areas, located outside the landslide, would have a null velocity. Consequently, displacement registered 
Table 3. Characteristics and precisions of displacement maps (with $\mu$ the average and $\sigma$ the standard deviation of data).

\begin{tabular}{|c|c|c|c|c|c|}
\hline & $74-83$ & $83-88$ & $88-91$ & $91-95$ & $95-99$ \\
\hline Retained precision in $\mathrm{m}$ & 4.9 & 10.4 & 8.2 & 13.8 & 4.9 \\
\hline Retained precision in $\mathrm{cm} /$ day & 0.15 & 0.59 & 0.74 & 0.96 & 0.34 \\
\hline$\%$ of eliminated points by statistic law $(\mu \pm 6 \sigma)$ & 0.7 & 0.0 & 0.2 & 0.03 & 0.003 \\
\hline $\begin{array}{l}\% \text { of eliminated points after sorting by sense of } \\
\text { displacements }\end{array}$ & 6.1 & 9.3 & 7.0 & 4.7 & 5.1 \\
\hline
\end{tabular}

on stable areas could be considered as a good evaluation of the precision of displacement maps. The precision is evaluated by plotting the average displacement, computed on a sliding window on stable areas, relative to the size of this window (Fig. 5). The average displacement becomes independent of the size of the window when the size of this window becomes large enough (Fig. 5). Precision values obtained by this way are included between 4.9 and $13.8 \mathrm{~m}$, that corresponds to an error bar for velocity maps included between 0.15 and $0.96 \mathrm{~cm} /$ day (Table 3 ). It appears quite impossible to evaluate quantitatively the precision of direction maps. Indeed, directions of displacements are randomly distributed on stable areas. So it seems that no preferential artificial displacement direction strongly alters the computed directions. Consequently, an area which presents homogeneous direction values in the landslide can be considered significant for the interpretation.

Loss of coherence is sometimes observed during the correlation phase because of the change in the surface aspect between the acquisitions of the two images. So, some points cannot be correlated. Moreover, some points are correlated even if they do not represent the same object. For example, two different neighbouring trees in a dense forest can be correlated because of their geometrical similarity. These bad correlated points have to be eliminated from displacement maps. Generally, the correlation quality is controlled by the correlation coefficient. Nevertheless, during multi-temporal correlation, this coefficient can be high even if directions of displacements appear unrealistic relative to the main slope direction of the mountain side. Consequently, it was decided to eliminate these bad correlated points using their sense of displacements. One point, registering a movement larger than the error bar of the amplitude map, but which presents an unrealistic direction of displacement, is then eliminated. It is then represented in white on displacement maps. The amount of removed points after this sorting step is less than $10 \%$ (Table 3). A statistic sorting is applied too. It allows to eliminate points which present amplitude of displacement really larger than maximal amplitudes of movements on the landslide. Thus, points with displacement amplitude larger than $\mu \pm 6 \sigma$ in absolute (with $\mu$ the average and $\sigma$ the standard deviation of data) are removed. This sorting step preserves more than $99 \%$ of remaining points (Table 3). Among all data, displacement maps of 1983-1988 and 1991-1995 present the worst quality because of the important changes

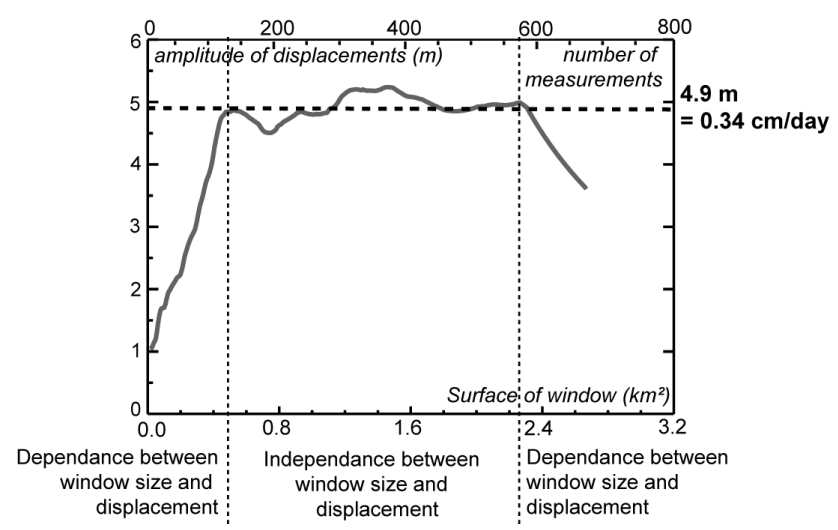

Fig. 5. Evaluation of the precision of amplitudes of displacements, example of 1995-1999.

of surface state during these time intervals, due to important scree slope development.

EDM are registered on the la Clapière landslide since 1982 (Follacci, 1999). The distances between targets and theodoliths are available between 1 November 1982 and 6 June 1999 for 13 targets located throughout the landslide. As theodoliths are located in front of the landslide at an elevation around $1360 \mathrm{~m}$ and at a distance larger than $1000 \mathrm{~m}$ from targets, the registered movements can be compared to horizontal displacements measured by image correlation on targets location (Casson, 2004). Figure 6 shows the good correlation between amplitude of EDM and amplitude of horizontal displacements calculated using image correlation, both for targets in movements within the landslide (targets no. 23, 29 for example) and for targets located on stable areas (target no. 25 for example) (Delacourt et al., 2004).

\subsection{Conceptual models}

These surface data can be used to analyse qualitatively the slip surface geometry of landslides, using conceptual models. Two major types of landslide are distinguished according to the geometry of the slip surface (Varnes, 1978): rotational landslides are characterized by a curved slip surface and translational landslides are characterized by a planar or nearly planar slip surface (Figs. 7a and 7b). In this second case, material moves along the planar surface without rotation. Nevertheless, the slip surface is often listric at the 

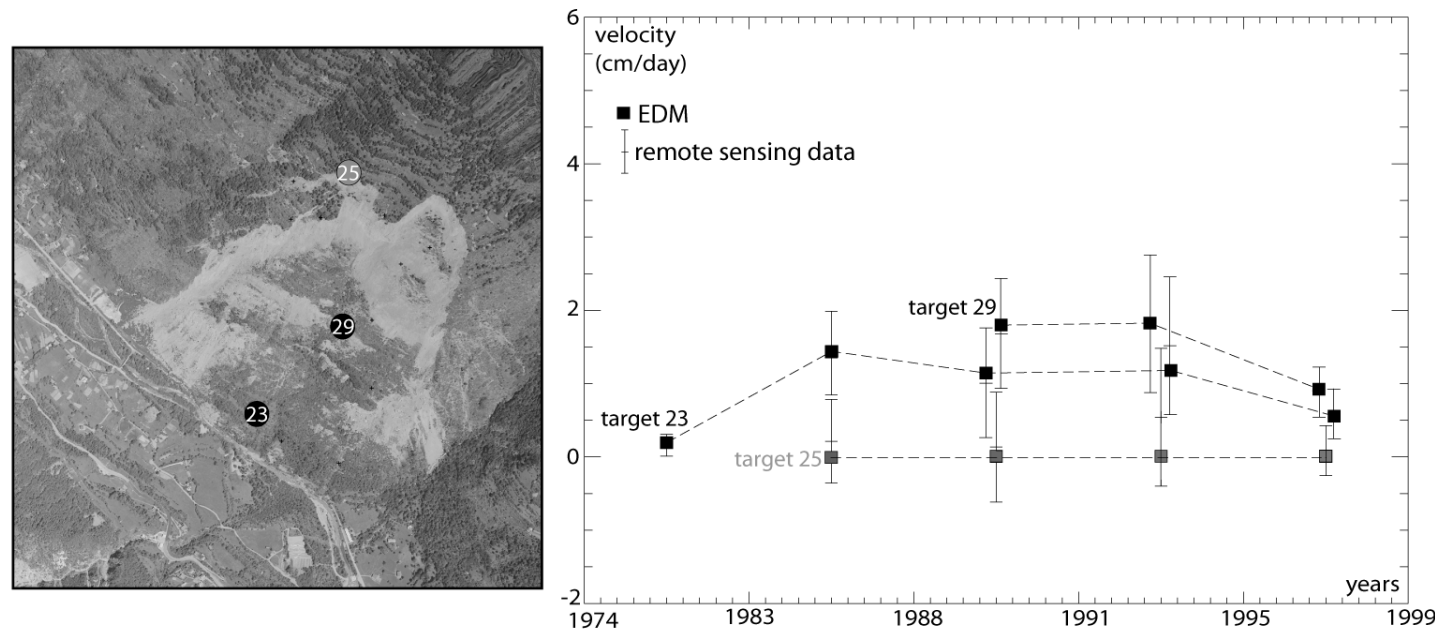

Fig. 6. Validation of displacement data - Amplitudes of EDM are correlated with amplitudes obtained by image correlation, example of targets no. 23, 29 and 25 .
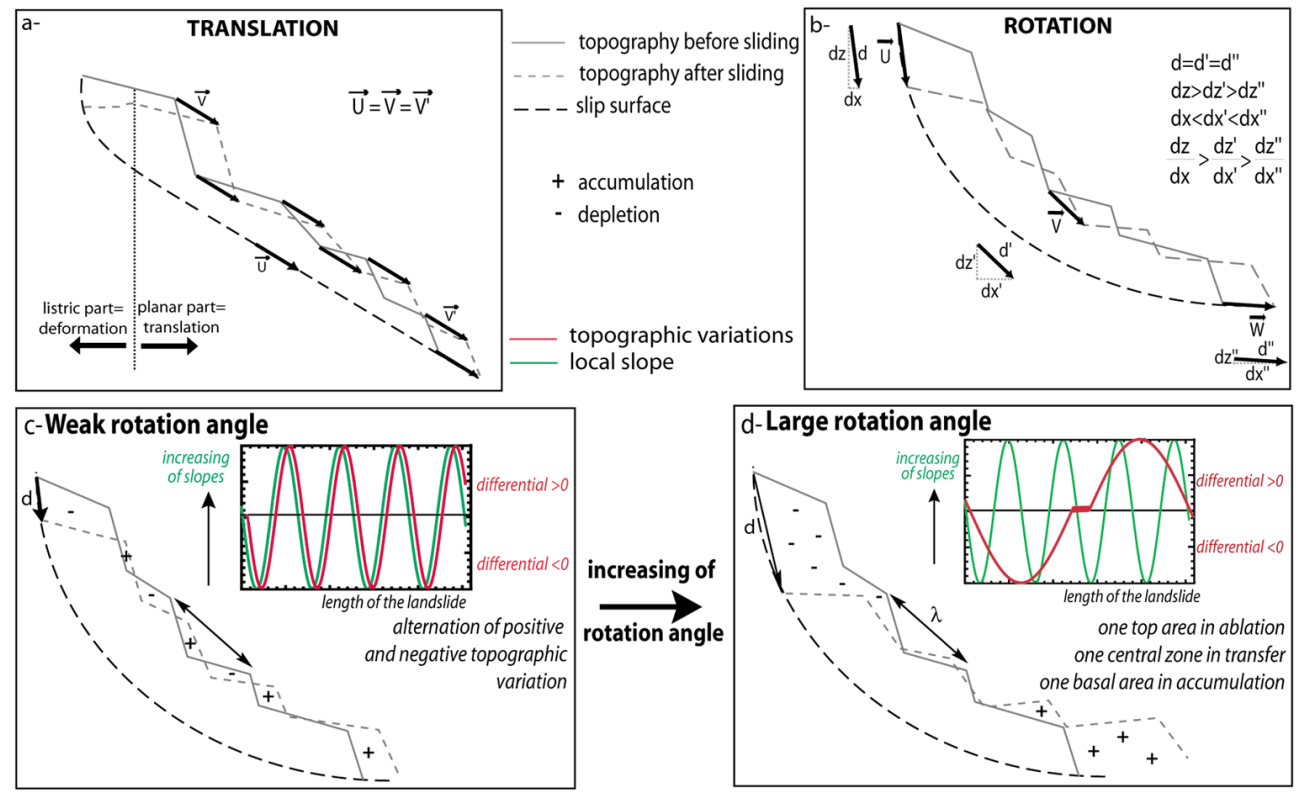

Fig. 7. Conceptual models which related surface displacements and topographic variations to slip surface geometry: (a) theoretical distribution of displacement vectors in a uniform translational landslide, (b) theoretical distribution of displacement vectors in a rotational landslide, (c) (d) relation between rotation angle and distribution of topographic variations, with $\lambda$ the characteristic wave length of the topography and $\boldsymbol{d}$ the displacement vectors. A rotation with a weak angle is presented on (c) and the case of a large rotation angle on (d).

top (Fig. 7a) of the landslide (Hutchinson, 1988; Cruden and Varnes, 1996).

Distribution of displacement vectors and of topographic variations is characteristic of the type of landslide (Hutchinson, 1983). Under the assumptions described in the introduction of part 3, a uniform translational landslide is characterized by displacement vectors that are all equal, along a profile crossing the landslide from top to bottom (Fig. 7a). A rotational landslide presents for its part a decrease of the ratios of vertical to horizontal displacements, from top to bottom of the landslide (Dikau, 1996) (Fig. 7b). Moreover, if there is no internal deformation and no boundary conditions, the norm of displacement vectors remains constant from top to bottom of the rotational landslide.

For rotational landslide, distribution of topographic variations is a function of the rotation angle and of the dominant topographic heterogeneities. For a dominant topographic wave length of the same order than the amplitude of displacements, a weak angle of rotation produces an alternation of positive and negative vertical variations of topography (Fig. 7c). For large rotation angles, landslide appears divided in three areas: an upper one in depletion, a central one in transfer and a basal one in accumulation (Fig. 7d).

Boundary conditions and/or the decrease of driving force 

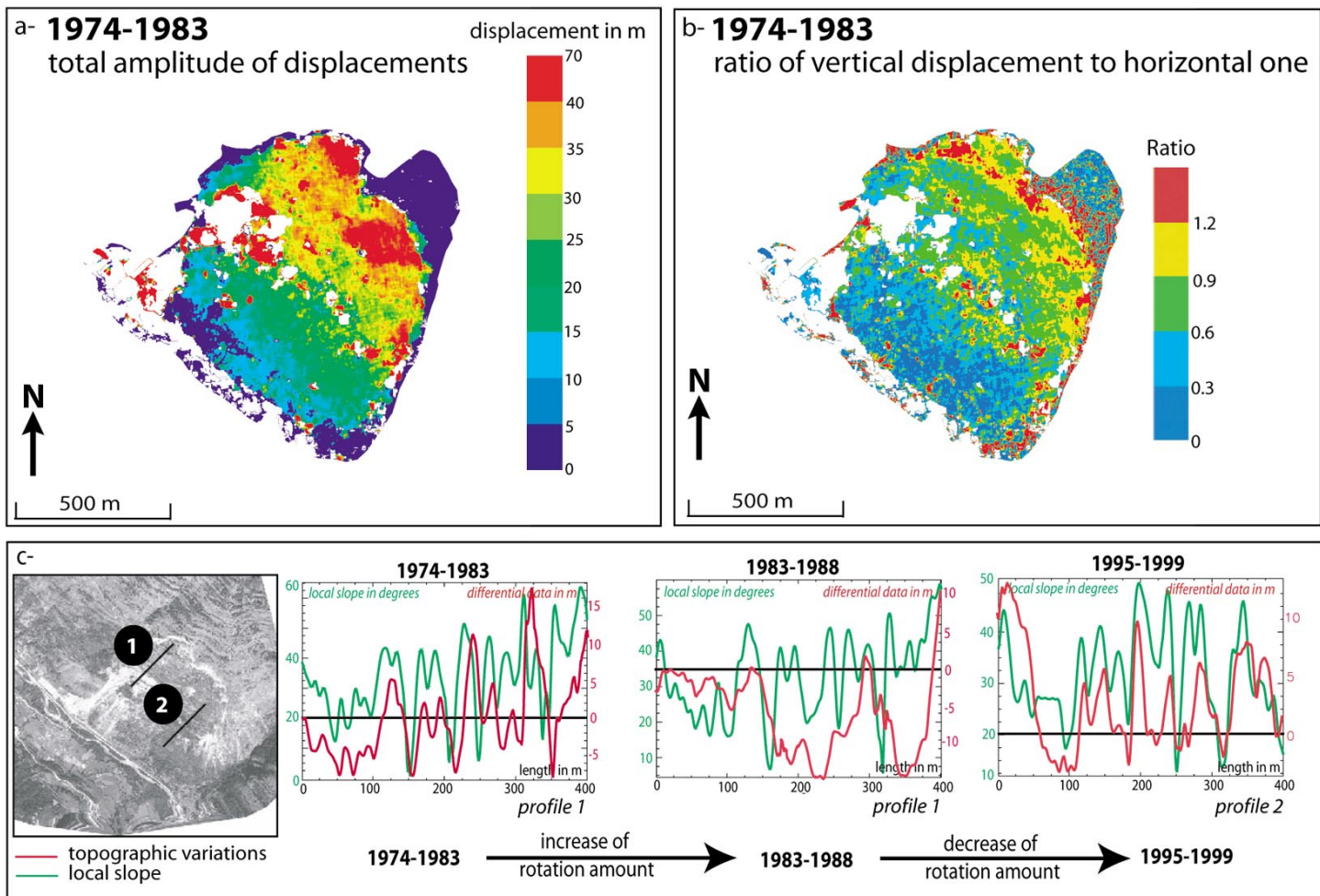

$1983-1988$
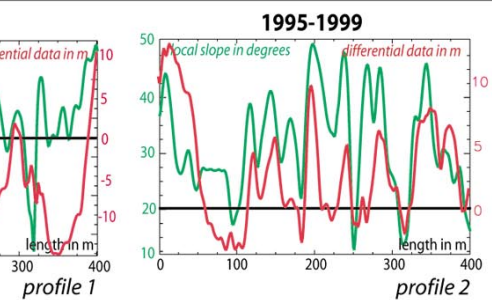

1983-1988

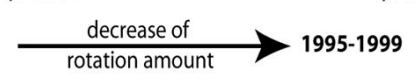

Fig. 8. Characterization of the slip surface geometry of the main body of the La Clapière landslide. (a) Distribution of total amplitude of displacements observed during the time interval 1974-1983. These amplitudes decrease from top to bottom of the main body of the landslide. (b) Distribution of ratios of vertical displacements to horizontal ones observed during the period 1974-1983. These ratios decrease from top to bottom of the main body of the landslide. (c) Distribution of topographic variations along two profiles in the La Clapiére landslide for three times intervals 1974-1983, 1983-1988 and 1995-1999. The correlation between local slopes variations and differential data distribution is only visible for 1974-1983 and 1995-1999. This correlation is lost between 1983 and 1988 (profile 1 presents only an ablation area because it is located in the top part of the landslide). These suggest an increase of the amount of rotation during 1983-1988 followed by a decreasing after 1995.

from top to bottom, due to the decrease of slip surface dip, produce the decrease of total amplitude of displacements from top to bottom of the landslide (Dikau, 1996). Moreover, if volume of the landslide remains almost constant, the decrease of displacement amplitude is associated with a deformation of the bottom of the landslide (Dikau, 1996), implying an apparent uplift. This deformation can erase the topographic heterogeneities and reduce the area of the transfer zone in the middle of the landslide.

\section{Results}

Conceptual models are applied to the la Clapière landslide using displacement maps and differential DEMs, of the time interval 1974-1999. This analysis focuses on the main body of the la Clapière landslide, without considering the top superimposed landslide. Two major scree slopes can be pointed out on the La Clapière landslide. These scree slopes are not interpreted because they are associated to superficial displacements. These scree slopes, located on basal sides of the landslide, are characterized by a loss of coherence on velocity maps due to important surface changes between the successive acquisitions of images. These areas appear in white on displacement maps because of the sorting steps of points. In a first time, the main slip surface geometry of the la Clapière landslide is characterised. Then, its spatial and temporal evolution is discussed.

\subsection{Main landslide slip surface}

Velocity maps of the la Clapière landslide show clearly that displacement vectors are not all equal on the landslide between 1974 and 1999 (Fig. 8a). It implies that the la Clapière landslide does not present a planar slip surface with a translational behaviour. Indeed, the ratio of vertical component of displacements to horizontal ones decreases from top to bottom of the landslide (Fig. 8b). Moreover, total amplitude of displacement decreases from top to bottom of the landslide (Fig. 8a) and an apparent uplift is registered at the base of the landslide. Pre-existing steps are not visible under the Iglière bar and the zone in transfer is not very spread. All these observations are characteristic of a non uniform rotational behaviour of this landslide along a curved slip surface. This is in agreement with some geological and morphologic studies realized on this landslide for 30 years (Follacci, 1987). 


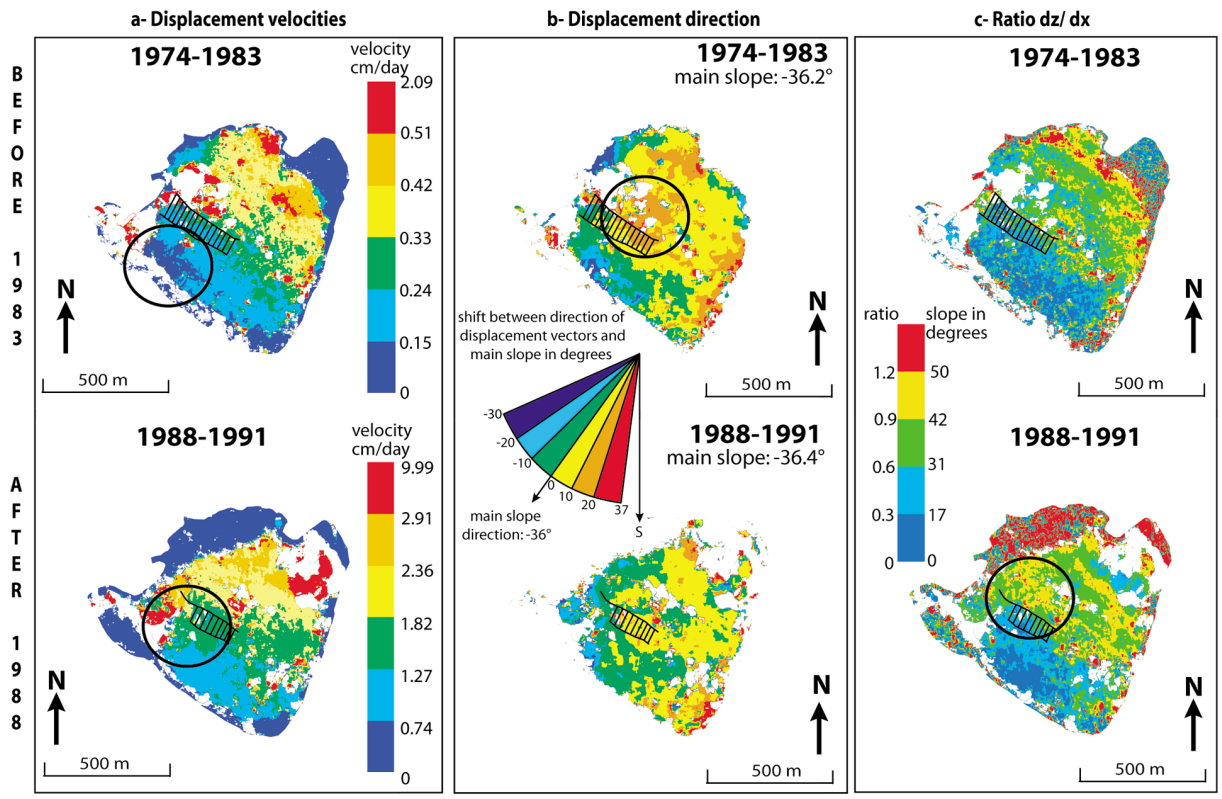

Fig. 9. Spatial and temporal evolution of the slip surface geometry of the main body of the la Clapière landslide - the location of the Iglière bar appears in black on each image. Black circles focus on interesting areas. (a) Distribution of velocity of total displacements before 1983 and after 1988. (b) Distribution of direction of displacements before 1983 and after 1988. (c) Distribution of ratio vertical displacements to horizontal ones before 1983 and after 1988.

The comparison between the wave length of the topography produced by the pre-existing steps and the distribution of differential topography is realized along two profiles which partly cross the landslide (Fig. 8c). An alternation between positive and negative variations of topography of the same wave length as topography is observed between 1974 and 1983 for the two profiles (Fig. 8c). This alternation disappears for the interval 1983-1991 whereas the topography produced by the steps is always visible (Fig. 8c). During this period, three zones can be defined within the landslide: a top one in depletion, a central one in transfer and a basal one in accumulation. After 1995, the alternation between positive and negative variations of topography is visible again but only on the profile 2 (Fig. 8c). Steps are no more visible on the topographic profile 1 . These observations suggest an increase of the rotation angle between 1983-1991 relative to the period 1974-1983, obviously correlated with the increase of the average velocity during the same period. After 1995, the rotation decreases. The disappearance of steps on the profile 1 can be explained by the development of a scarp in 1987 just above this area. This scarp development has probably generated an intense internal deformation that could have erased the steps.

\subsection{Spatial and temporal evolution of the slip surface}

As explained in the geological setting, the conceptual model of the La Clapière landslide developed by Follacci (1987), suggests that the slip surface was more extended in the $\mathrm{E}$ part than in the W part of the landslide before 1987.

Before 1983, velocity map of the la Clapière landslide shows a stable area at the base of the landslide that is more extended on the SW side of the landslide than on SE side (Fig. 9a). At the same time, the direction map points out displacements mostly directed in the $\mathrm{S}$ direction above the Iglière bar in the W part of the landslide (Fig. 9b), at more than $10^{\circ}$ degrees from the main slope direction. The remaining surface registers displacements mostly directed in the direction of the main slope. So, before 1983, the "barre d'Iglière" seems to limit the movements in the $\mathrm{W}$ part of the landslide. In the E part, the "barre d'Iglière" appears to be involved in the movements. These observations are in agreement with Follacci's model.

After 1988, the stable area of the SW part of the landslide is affected by movement with registered velocities higher than $1.2 \mathrm{~cm} /$ day (Fig. 9a). Moreover, from this date, all displacements throughout the landslide are homogeneous and directed along the main slope direction (Fig. 9b). So, after 1988, the "barre d'Iglière" is not an obstacle to displacements anymore in the $\mathrm{W}$ part of the landslide.

If it is assumed that velocity is independent of depth and that internal deformation is negligible, the dip of displacement vectors is equal to the slope of slip surface. Before 1983, these dips decrease from top to bottom of the landslide (Fig. 9c). This suggests a curved aspect of the slip surface from top to bottom of the landslide, that confirms its rotational behaviour. After 1988, the area just above the "barre d'Iglière" registers displacement vectors with high dip in the $\mathrm{W}$ part of the landslide. This suggests the development of a new slip surface or the propagation of the pre-existing slip surface below the Iglière bar.

In conclusion, the "barre d'Iglière" bounds the movements in the W part of the landslide before 1983. The slip surface 
probably only extends from top to the "barre d'Iglière" in this area. Displacements are then controlled by this lithologic unit and by the N20 central fault. After 1988, the boundary effect of the "barre d'Iglière" disappeared. The "barre d'Iglière" is implied in the global movement. The slip surface probably extends from top to base of the landslide in the $\mathrm{W}$ part of the landslide since this date.

This spatial evolution of the slip surface during time can be linked to the activity peak of the landslide in 1987 (Follacci et al., 1988b; Follacci, 1999). The intensification of movements induced the development of a new scarp in the NW upper part of the landslide. One visible consequence is the stabilization of the NW lobe of the landslide. Moreover, it could have modified the state of stress within the landslide (Follacci et al., 1988b). This change in the state of stress could have induced the evolution of the slip surface geometry in the $\mathrm{W}$ part of the landslide.

\section{Discussion and conclusion}

This paper presents a methodology for extracting surface data from DEMs and orthoimages. Velocity maps, direction maps and differential maps which are generated by this processing allow to monitor landslide activity by measuring surface displacements and topographic variations with a precision of a few meters. Displacement maps have been validated using EDM. This method is particularly efficient for monitoring slow landslides characterized by pluri-metric displacements per years. Indeed, faster landslides would present important surface changes which would not allow to register surface displacements by image correlation at the time resolution of some years. Concerning very slow landslides, our methodology is not enough precise at this date for registering centimetric movements per years. Nevertheless, very simple improvements in the methodology of DEMs generation would enhance the detection threshold. For example, the use of accurate absolute points during the orientation of cameras would produce a real improvement in the final absolute accuracy of DEMs. On the other hand, if image correlations are not possible because of the changing of surface state, differential topography can be used in order to estimate the intensity of movements. Indeed, in this study the variation of the rotation amount is in agreement with variations of velocities of the La Clapière landslide.

In a second time, the potential of these data for slip surface characterization is pointed out. Without denying the necessity of geophysical investigations to image slip surface, we have shown that remote sensing could be an alternative and a complementary method to study the internal geometry of landslide. Indeed, the rotational behavior of the La Clapière landslide can be suspected only from surface data, in agreement with bibliographic data. Secondly, the spatial and temporal evolution of the geometry of the slip surface is pointed out from our data set. A modification in the geometry of the slip surface at the level of the Iglière bar after 1988 is pointed out.
This study is realised under very strong assumptions and only in 2D. It implies that the intense fracturation of the area and the possibility for this landslide to behave differently in space are not taking into account. Nevertheless, at first order, displacement data and topographic variations are homogeneous on the main body of the landslide. Consequently, at the scale of the landslide, this assumption is realistic. We do not take into account deformation and 3D effect. Nevertheless, a westward propagation of deformation is necessary to mechanically explain the evolution of the slip surface, proposed in this paper. Consequently, despite our hypothesis, the methodology allows to suspect some large heterogeneities in the slip surface geometry for the La Clapière landslide. A study at lower spatial scale would have to take into account some mechanical considerations as the deformability in order to explain the evolution of the slip surface, presented in this paper.

One major perspective of this study is to propose a simple methodology in order to help in situ investigations of the subsurface. For example, suspicions of large heterogeneities in slip surface geometry can be used in order to well distribute geophysical profiles or boreholes. Moreover, a quantitative characterization of the slip surface is possible by developing simple geometric models to image the slip surface and to evaluate its depth. Finally, other sites, with faster or lower displacements, must be tested in order to perform our methodology, particularly by improving the resolution of measurements.

Acknowledgements. This work is financially supported by CNES (Centre National des Etudes Spatiales), the IMAGE SARL company and the French INSU SAMOA project (French Ministry of Research). We acknowledge too Y. Guglielmi and the CETE (Centre des Etudes Techniques de l'Equipement) for providing EDM of the La Clapière landslide.

Edited by: M. Jaboyedoff

Reviewed by: G. B. Crosta, Y. Guglielmi, and T. Lebourg

\section{References}

Baratoux, D., Delacourt, C., and Allemand, P.: High-resolution digital elevation models derived from Viking Orbiter images: Method and comparison with Mars Orbiter Laser Altimeter Data, J. Geophys. Res., 106, 32 927-32 941, 2001.

Berardino, P., Costantini, M., Franceschetti, G., Iodice, A., Pietranera, L., and Rizzo, V.: Use of differential SAR interferometry in monitoring and modelling large slope instability at Maratea (Basilicata, Italy), Engineering Geology, 68, 31-51, 2003.

Bigot-Cormier, F., Braucher, R., Guglielmi, Y., Bourlès, D.L., Dubar, M. and Stephan, J.F.: Chronological constrains of the la Clapière landslide ( $44^{\circ} 15 \mathrm{~N}, 6^{\circ} 56 \mathrm{E}$, France): geomorphology and cosmonucleides approaches, AGU-EGS-EGU First Joint Assembly, Nice, 2003.

Bishop, K. M.: Determination of Translational Landslide Slip Surface Depth Using Balanced Cross Sections, Environmental \& Engineering Geoscience, 2, 147-156, 1999.

Bogoslovski, V. A. and Ogilvy, A. A.: Geophysical methods for the investigation of landslides, Geophysics, 42, 3, 562-571, 1977. 
Cappa, F. Guglielmi, Y., Soukatchoff, V. M., Mudry, J., Bertrand, C., and Charmoille, A.: Hydromechanical modeling of a large moving rock slope inferred from slope levelling to spring longterm hydrochemical monitoring: example of the La Clapière landslide (Southern Alps, France), J. Hydrol., 291, 67-90, 2004.

Casson, B. : Apports de l'imagerie optique haute resolution pour l'étude 3D des glissements de terrain, Université Claude Bernard Lyon 1, 277, 2004.

Casson, B., Delacourt, C., Baratoux, D., and Allemand, P.: Seventeen years of the "La Clapière landslide evolution analysed from ortho-rectified aerial photographs, Engineering Geology, 68, 123-139, 2003.

Compagnon, F., Guglielmi, Y., Mudry, J., Follacci, J.-P., and Ivaldi, J.-P.: Chemical and isotopic natural tracing of seepage waters in an important landslide: example from La Clapière landslide (Alpes-Maritimes, France), C. R. Acad. Sci. Paris, Earth \& Planetary Sciences, 325, 565-570, 1997

Cruden, D. M. and Varnes, D. J.: Landslide types and processes, in: Landslides: Investigation and Mitigation, edited by: Turner, A. K. and Schuster, R. L., Transportation Research Board, Special Report, 247, 36-75, 1996.

Delacourt, C., Allemand, P., Casson, B., and Vadon, H.: Velocity field of the "La Clapière" landslide measured by the correlation of aerial and QuickBird images, Geophys. Res. Lett., 31, 15, L15619, doi: 10.1029/2004GL020193, 2004.

Dikau, R., Brunsden, D., Schrott, L., and Ibsen, M.-L.: Landslide recognition: Identification, Movement and Causes, John Wiley and Sons Ltd, West Sussex, UK, 251, 1996.

Ehlert, K. W.: Origin of the mile-long valley located northerly of the ancient Portuguese Bend landslide, Paolo Verdes Peninsula, southern California, in: Landslides and Landslides Mitigation in Southern California, edited by: Ehlig, P. L., Guidebook and Volume: Cordilleran Section of the Geological Society of America, 167-172, 1986.

Follacci, J.-P.: Les mouvements du versant de la Clapière à SaintEtienne-de-Tinée (Alpes-maritimes), Bulletin de liaison du laboratoire des Ponts et Chaussées, 150-151, 39-54, 1987.

Follacci, J.-P.: Seize ans de surveillance du glissement de la Clapière (Alpes-Maritimes), Bulletin des laboratoires des Ponts et Chaussées, 220, 35-51, 1999.

Follacci, J.-P., Guardia, P., and Ivaldi, J.-P.: Geodynamic framework of la Clapière landslide (Maritime Alps, France), 5th Symposium international sur les glissements de terrain, 1323-1327, 1988a.

Follacci, J.-P., Gastaud, J.-P., and Durville, J.-L.: Le point sur l'évolution des déplacements dans le glissement de la Clapière (Alpes-Maritimes), Bulletin de liaison du laboratoire des Ponts et Chaussées, 158, 107-109, 1988b.

Fruneau, B., Achache, J., and Delacourt, C.: Observation and modelling of the Saint-Etienne-de-Tinée landslide using SAR interferometry, Tectonophysics, 265, 181-190, 1996.

Gili, J. A., Corominas, J., and Rius, J.: Using Global Positioning System techniques in landslide monitoring, Engineering Geology, 55, 167-192, 2000.

Guglielmi, Y., Bertrand, C., Compagnon, F., Follacci, J.-P., and Mudry, J.: Acquisition of water chemistry in a mobile fissured basement massif: its role in the hydrogeological knowledge of the La Clapière landslide (Mercantour massif, southern Alps, France), J. Hydrol, 229, 138-148, 2000.

Gunzburger, Y.: Apport de l'analyse de la fracturation et de la modélisation numérique à l'étude du versant instable de La Clapière (Saint-Etienne-de-Tinée, Alpes-Maritimes), rapport DEA PAE3S, Laboratoire Environnement, Géomécanique, Ou- vrages (LAEGO) - Ecole nationale Supérieure des mines de Nancy, 2001.

Gunzburger, Y. and Laumonier, B.: Origine tectonique du pli supportant le glissement de terrain de la Clapière (Nord-Ouest du massif de l'Argentera-Mercantour, Alpes du Sud, France) d'après l'analyse de la fracturation, C. R. Géosciences, 334, 415422, 2002.

Hanssen, R. F.: Radar Interferometry: Data Interpretation and Error Analysis, Kluwer Academic Publishers, Dordrecht, 328, 2001.

Hutchinson, J. N.: Methods of locating slip surfaces in landslides, Bulletin of the Association of Engineering Geologists, 20, 235252, 1983.

Hutchinson, J. N.: Morphological and geotechnical parameters of landslides in relation to geology and hydrology, general report, in: Landslides, edited by: Bonnard, C., Proceedings of the 5th International Symposium on Landslides, Rotterdam, Netherlands, 1, 3-35, 1988 .

Israil, M. and Pachauri, A. K.: Geophysical characterization of a landslide site in the Himalayan foothill region, Journal of Asian Earth Sciences, 22, 253-263, 2003.

Kääb, A.: Monitoring high-mountain terrain deformation from repeated air- and spaceborne optical data: examples using digital aerial imagery and ASTER data, bISPRS Journal of Photogrammetry \& Remote Sensing, 57, 39-52, 2002.

Kraus, K. and Waldhäusl, P.: Photogrammetry, Fundamentals and Standard Processes, Hermès editor, Paris, 407, 1994.

Lebourg, T., Tric, E., Guglielmi, Y., Cappa, F., Charmoille, A., and Bouissou, S.: Geophysical survey to understand failure mechanisms involved on Deep Seated Landslides, Geophysical Research Abstracts, European Geophysical Society, EGS-AGUEUG Joint Assembly, Nice, 5, 01043, 2003.

Malet, J.-P., Maquaire, O., and Calais, E.: The use of Global Positionning System techniques for the continuous monitoring of landslides: application to the Super-Sauze earthflow (Alpes-deHaute-Provence, France), Geomorphology, 43, 33-54, 2002.

Maquaire, O., Flageollet, J.-C., Malet, J.-P., Schumtz, M. , Weber, D. , Klotz, S., Albouy, Y., Descloîtres, M., Dietrich, M., Guérin, R. and, Schott, J.J.: A multidisciplinary study for the knowledge the Super-sauze earthflow in Callovian-Oxfordian black marls ( Super-Sauze, Alpes-de-Hautes-Provence, France), Revue française de géotechnique, 95-96, 15-32, 2001

Mauritsch, H. J., Seiberl, W., Arndt, R., Römer, A., Schneiderbauer, K., and Sendlhofer, G.: Geophysical investigations of large lanslides in the Carnic Region of southern Austria, Engineering Geology, 56, 373-388, 2000.

Mikhail, E., Bethel, J. S., and McGlone, J. C.: Introduction to Modern Photogrammetry, Hardcover edition, New-York, 479, 2001

Mora, P., Baldi, P., Casula, G., Fabris, M., Ghirotti, M., Mazzini, E., and Pesci, A.: Global Positioning Systems and digital photogrammetry for the monitoring of mass movements: application to the $\mathrm{Ca}$ ' di Malta landslide (northern Apennines, Italy), Engineering Geology, 68, 103-121, 2003.

Powers, P.S., Chiarle M., and Savage, W. Z.: A Digital Photogrammetric method for measuring horizontal surficial movements on the Slumgullion Earthflow, Hinsdale County, Colorado, Computers \& Geosciences, 22, 6, 651-663, 1996

Quenot, X: Etude du glissement de La Clapière, modélisation du phénomène de rupture, rapport DEA PAE3S, Laboratoire Environnement, Géomécanique, Ouvrages (LAEGO) - Ecole nationale Supérieure des mines de Nancy, 2000.

Rizzo, V.: GPS monitoring and new data on slope movements in the Maratea Valley (Potenza, Basilicata), Phys. Chem. Earth, 27, 
1535-1544, 2002.

Scullin, C. M.: Subsurface exploration using bucket auger borings and down-hole geologic inspection, Bulletin of Engineering Geology, 31, 91-105, 1994.

Serratrice, J.-F.: Glissement de la Clapière. Comparaison des MNTs de 1970 à 1997, Journées de mécanique des Sols et des Roches des LPC, Laboratoires des Ponts et Chaussées, Nancy, 2001.

Soukatchoff, V. M. and Guglielmi, Y.: Modeling by distinct elements of gravitational toppling mechanism. Application to the modeling of the landslide of la Clapière (Saint-Etienne-deTinée, Alpes-Maritimes). Revue française de géotechnique, 9596, 133-142, 2001.

Squarzoni, C. : Mesure des champs de déplacement et modélisation numérique des glissements de terrain, thèse de doctorat, Université Claude Bernard Lyon 1, 213, 2003.

Squarzoni, C., Delacourt, C., and Allemand, P.: Nine years of spatial and temporal evolution of the La Valette landslide observed by SAR interferometry, Engineering Geology, 68, 53-66, 2003.
Squarzoni, C., Delacourt, C., and Allemand, P.: Differential singlefrequency GPS monitoring of the la Valette landslide (French Alps), Engineering Geology, 2005.

Vadon, H. and Massonnet, P.: Earthquake displacement fields mapped by very precise correlation, Complementarity with radar interferometry, IGARSS proc, 2002.

Van Westen, C. J., and Getahun, F. L.: Analysing the evolution of the Tessina landslide using aerial photographs and digital elevation models, Geomorphology, 1347, 1-13, 2003.

Varnes, D. J.: Slope movements: type and processes, in: Landslides Analysis Control, edited by: Schuster, R. L. and Krisek, R. J., Transp. Res. Board., Special Report, 176, 11-33, 1978.

Weber, D. and Herrmann, A.: Contribution de la photogrammétrie numérique à l'étude spatio-temporelle de versants instables: l'exemple du glissement de terrain de Super-Sauze (Alpes-deHautes-Provence, France), Bulletin de la Société Géologique de France, 171, 6, 637-648, 2000. 